\title{
Quality improvement programmes were effective for depression in managed primary care
}

Wells $K B$, Sherbourne $C$, Schoenbaum $M$, et al. Impact of disseminating quality improvement programs for depression in managed primary care: a randomized controlled trial. JAMA 2000 Jan 12;283:212-20.

QUESTION: In managed primary care practices, does implementation by practices of quality improvement (QI) programmes for depression improve quality of care, health outcomes, and employment rates?

\section{Design}

Clinic randomised \{allocation concealed*\}†, unblinded*, controlled trial with 1 year of follow up.

Setting

46 primary care clinics in 6 US managed care organisations.

\section{Participants}

1356 patients (mean age 44 y, $71 \%$ women) with current depressive symptoms and either 12 month, lifetime, or no depressive disorder who intended to use the clinic as a source of care for the next 12 months. Patient exclusion criteria were $<18$ years of age, acute medical emergency, did not speak English or Spanish, or did not have either insurance or a public pay arrangement that covered care delivered by the mental health specialists used in the interventions of this study.

\section{Intervention}

Matched clinics were allocated to usual care (mailing of practice guidelines, 16 clinics, 443 patients) or to 1 of 2 QI programmes (30 clinics, 913 patients). The QI programmes involved institutional commitment to QI, training local experts and nurse specialists to provide clinician and patient education, identification of a pool of potentially depressed patients, and either nurses for medication and follow up (QI-meds) or access to trained psychotherapists (QI-therapy).

\section{Main outcome measures}

Process of care (use of antidepressant medication, mental health specialty counselling visits, medical visits for mental health problems, any medical visits), health outcomes (probable depression and health related quality of life), and employment.

\section{Main results}

Sources of funding: Agency for Health Care Policy and Research; National Institute of Mental Health,

Research Scientist

Award;Research Center

on Managed Care for

Psychiatric Disorders;

The John D and

Catherine T

MacArthur

Foundation.

For correspondence: Dr K B Wells, RAND, 1700 Main Street,

Santa Monica, CA

90407, USA. Fax +1

3107943724.
At 6 months, $51 \%$ of patients in the QI group compared with $40 \%$ of patients in the control group had counselling or used antidepressant medication at an appropriate dosage $(\mathrm{p}<0.001)$, with a similar pattern at 12 months $(59 \%$ v $50 \%, \mathrm{p}=0.006)$. At 6 months, $48 \%$ of patients in the QI group compared with $37 \%$ in the control group had a medical visit for mental health problems $(\mathrm{p}=0.001)$, but a similar percentage had any general medical visit and QI patients were more likely to have seen a mental health specialist at 6 months $(40 \% v$ $27 \%, \mathrm{p}<0.001)$ and at 12 months $(29 \% v 23 \%, \mathrm{p}=0.03)$. At 6 months, $40 \%$ of QI patients compared with $50 \%$ of control patients met the criteria for probable depressive disorder $(\mathrm{p}=0.001)$, with a similar pattern at 12 months $(42 \%$ v 51\%, $\mathrm{p}=0.005)$. Initially employed QI patients were more likely to be working at 12 months compared with those in the control group $(p=0.05)$.

\section{Conclusion}

When managed primary care practices implemented quality improvement programmes, quality of care, mental health outcomes, and employment retention rates improved for patients with depressive symptoms.

*See glossary.

$\dagger$ Information provided by author.

\section{COMMENTARY}

Depression is expected to become the second leading cause of disability worldwide. Solid evidence exists of benefit from antidepressant medication, and from certain psychotherapies, provided under standardised conditions to depressed patients in primary care. And yet deficiencies remain in the quality of care for depression in many primary care settings. This study by Wells $e t$ al showed that in US managed primary care, a multifaceted intervention implemented by the practices themselves with modest study support, incorporating physician and nurse education, resulted in enhancements in the process of care, and improved patient outcomes. In contrast, in a recent randomised controlled trial in the UK, education for primary healthcare team members, based on clinical practice guidelines, produced no measurable improvements in outcome. ${ }^{1}$ Lack of benefit after physician education has similarly been reported in a US study. ${ }^{2}$ Why the difference? The intervention in the study by Wells $e t$ al included several additional elements: institutional commitment to, and investment in, the intervention; identification of depressed patients with recall by clinic nurses; patient follow up by nurses or therapists; direct training of therapists in efficacious therapy; direct patient education; and local audit with feedback. Systematic reviews of strategies for enhancing physician performance have highlighted the effectiveness of multifaceted interventions, ${ }^{3}$ and most elements of the intervention evaluated by Wells et al probably contributed to the observed benefit.

Tim Usherwood, MD, FRCGP, FRCP, DMS University of Sydney at Westmead Hospital Westmead, New South Wales, Australia

1 Thompson C, Kinmonth AL, Stevens L, et al. Effects of a clinical-practice guideline and practice-based education on detection and outcome of depression in primary care: Hampshire Depression Project randomised controlled trial. Lancet 2000;355:185-91.

2 Lin EH, Katon WJ, Simon GE, et al. Achieving guidelines for the treatment of depression in primary care: is physician education enough? Med Care 1997;35:831-42.

3 Davis DA, Taylor-Vaisey A. Translating guidelines into practice. A systematic review of theoretic concepts, practical experience and research evidence in the adoption of clinical practice guidelines. CMAJ 1997;157:408-16. 